\title{
Impérios Alimentares e Segurança Alimentar: As Contradições da Relação Produção- Consumo na Comunidade Morrinhos, Santa Luz/PI
}

Food Empires and Food Security: The Contradictions of the Production-Consumption Relationship in the Community Morrinhos, Santa Luz / PI

Adriana Dias de Sousa ${ }^{1}$, Valcilene Rodrigues da Silva ${ }^{1}$

Universidade Federal do Piauí ${ }^{1}$

adrianadiasjorge@gmail.com

DOI: https://doi.org/10.52719/bjas.v2i1.2945

\section{RESUMO}

O presente artigo teve o objetivo de analisar em que medida os camponeses da comunidade Morrinhos garantem a sua segurança alimentar, bem como, as influências sofridas nessa comunidade pelos impérios alimentares. A metodologia utilizada sustenta-se na pesquisa qualitativa, considerando que ela responde a questões mais peculiares. Os resultados da pesquisa mostram a relação contraditória entre os camponeses e os impérios alimentares. De um lado tem-se uma produção diversificada dos camponeses garantindo uma relativa autonomia e segurança alimentar e nutricional, e por outro percebe-se que diversos fatores como as condições climáticas, a sucessão rural e a mídia influenciam na adesão de produtos dos impérios alimentares por tais camponeses e com eles muitas vezes a insegurança alimentar e diversos problemas de saúde.

Palavras-Chave: Campesinato. Agroecologia. Impérios Agroalimentares. Soberania Alimentar.

\begin{abstract}
The purpose of this article was to analyze the extent to which the peasants of the Morrinhos community guarantee their food security, as well as the influences suffered in this community by the food empires. The methodology used is based on qualitative research, considering that it answers more peculiar questions. The survey results show the contradictory relationship between peasants and food empires. On the one hand, there is a diversified production by the peasants guaranteeing relative autonomy and food and nutritional security, on the other, it can
\end{abstract}


be seen that several factors such as climatic conditions, rural succession and the media influence the adhesion of food empires products by such farmers and with them often food insecurity and various health problems.

Keywords: Food Sovereignty. Peasantry. Agroecology. Agrifood Empires.

\section{INTRODUÇÃO}

$\mathrm{O}$ ato alimentar possibilita que natureza e cultura se integrem na construção de identidades sociais e culturais, e expressa os modos de vida. Desse modo, a alimentação vai além dos aspectos nutricionais, pois envolve cultura, como o saber-fazer herdado entre as gerações constituintes de um modo de vida (Pereira, 2015). No entanto, no contexto de globalização no qual estamos inseridos, nota-se verdadeiros impérios alimentares. Esses impérios, totalmente capitalistas, contribuem no processo de homogeneização da cultura e de perda da biodiversidade alimentar.

Enquanto os povos da cidade são mais dependentes, os povos do campo apresentam-se como uma das mais significativas forças de resistência na era da globalização tendo a terra como pilar central, tanto do ponto de vista material como simbólico (Ploeg, 2008). No entanto, os camponeses não estão isentos a pressão exercida pelos impérios alimentares. O autor afirma que a contraditória condição camponesa consiste na luta por autonomia e por progresso em um contexto caracterizado por padrões de dependência múltiplos e pelo processo de exploração e marginalização associados. Ou seja, o império e o campesinato, onde quer que se localizem, se envolvem em contradições e conflitos.

O processo de desenvolvimento da agricultura da comunidade Morrinhos, Santa Luz/PI, recorte empírico deste estudo, se desenvolveu por muitos anos a partir de quintais produtivos ou arredores de casa. Desse modo, garantiam uma autonomia relativa em relação a esses impérios e, portanto, relativa segurança e soberania alimentar. No entanto, observamos que o modo de vida desses camponeses tem sofrido interferências externas e grandes transformações nos últimos anos. Esse contexto tem levado os moradores da comunidade, a lutar cada vez mais e persistir para assegurar os próprios direitos com relação à terra, bem como, preservar seu modo de vida, sua cultura e seu modo de produzir.

Diante dessa problemática a pesquisa parte da seguinte pergunta: Diante do contexto de transformações existentes no meio rural, como os camponeses da comunidade Morrinhos 
garantem sua soberania alimentar? Nota-se nessa comunidade adesão aos produtos dos impérios alimentares? Logo, o objetivo geral foi analisar em que medida os camponeses da comunidade Morrinhos garantem a sua soberania alimentar, bem como, as influências sofridas nessa comunidade pelos impérios alimentares.

O trabalho justifica-se pela necessidade de compreender como ocorre as disputas entre camponeses e impérios alimentares no Piauí, especialmente em área de fronteira agrícola, como é o caso do Sudoeste do estado, em que o agronegócio avança a cada dia e com ele os diversos pacotes tecnológicos, assim como a lógica de produção e consumo capitalista. Além disso, compreendemos que os resultados obtidos na pesquisa podem contribuir com outras comunidades com aspectos similares a Morrinhos e com possíveis políticas públicas de apoio ao campesinato na região. A motivação pessoal por esse tema tem a ver com uma vida inserida na agricultura, por ser filha de camponeses e desejar avançar nos estudos que envolvem essa categoria social.

A comunidade Morrinhos foi selecionada como referência empírica por ser uma comunidade inserida nesse contexto de mudanças e pelo acesso direto às pessoas da comunidade, o que proporcionou maior facilidade para a realização da pesquisa de campo. A metodologia utilizada sustenta-se na pesquisa qualitativa, considerando que ela responde a questões mais peculiares, se preocupa com o nível de realidade que não pode ser quantificado e considera crenças, valores e atitudes (Minayo, 2001). A pesquisa empírica utilizou-se de trabalhos de campo que foram realizados entre os meses de junho e setembro de 2019 no intuito de coletar dados, observar e realizar registros fotográficos que demonstram a realidade dos camponeses.

Dentre as técnicas de pesquisa usamos: o diário de campo, um instrumento para anotações, comentários e reflexão para uso do investigador. Nele se anotam todas as observações de fatos, acontecimentos, relações verificadas e experiências (Falkembach, 1987); e entrevistas abertas, aquela em que o entrevistador não segue um roteiro padronizado, mas explora uma questão central de acordo com os aspectos que considera significativos. Há liberdade total para o entrevistado se expressar (Marconi \& Lakatos, 2003). Realizamos entrevistas com 9 (algumas entrevistas tiveram participação de mais de um membro) das 15 famílias residentes na comunidade levando em consideração a disponibilidade delas para nos receber. 
A análise foi realizada de forma qualitativa, assim os dados das entrevistas e diário de campo foram selecionados a partir de categorias significativas para a análise como: aspectos sociais, atividades produtivas, consumo da produção local e compra de produtos insumos externos para daí verificar as relações existentes entre os aspectos teóricos e a realidade estudada. O referencial teórico se embasou na pesquisa bibliográfica, a partir da consulta em livros e artigos, o que contribuiu na análise, interpretação e sistematização dos resultados.

\section{CONTEXTO HISTÓRICO, SOCIAL E PRODUTIVO DA COMUNIDADE MORRINHOS, SANTA LUZ/PI}

A comunidade de Morrinhos encontra-se situada no município de Santa Luz, estado do Piauí e fica a 623 km da sua capital Teresina. De acordo com o Instituto Brasileiro de Geografia e Estatística [IBGE] (2010) esse município foi fundado em 1902, mas só teve emancipação em 25 de dezembro de 1962. Ele está localizado geograficamente na microrregião do Alto Médio Gurguéia, mesorregião do sudoeste Piauiense.

De acordo com a sinopse do censo do Instituto Brasileiro de Geografia e Estatística [IBGE] de 2010 disponibilizada no site da instituição, Santa Luz tinha cerca de 5.513 habitantes e $1.186 .839 \mathrm{~km}$. Na população estimada para 2019, considera-se que houve aumento para 5.860 habitantes (IBGE, 2019). Ainda segundo o site do IBGE dentre os produtos agrícolas produzidos no município estão: fava, feijão, milho, mandioca, banana, legumes, hortaliças, capim, e há também criações de gados, caprinos, ovinos, suínos e aves.

A excelência das condições físicas do 'Piauí' para os primeiros ocupantes reside, em primeiro lugar, nas
enormes possibilidades de criação de gado (abundância de pastos naturais onde proliferavam gramíneas
e leguminosas, fartos recursos hídricos e salubridade do clima) e, em seguida, a relativamente boa oferta
de produtos coletáveis e animais de caça [...]. (Martins et al, 2002, pp. 19-20).

A comunidade Morrinhos dista aproximadamente $11 \mathrm{~km}$ da cidade de Santa Luz, o que facilita o acesso dos moradores aos alimentos industrializados e promove a entrada dos produtos dos impérios alimentares nela. Os moradores estimam que a comunidade tenha, atualmente, 55 anos de existência e recebeu esse nome de Morrinhos, por ser constituída em grande parte por morros. Atualmente, há 15 famílias residentes na comunidade, algumas delas possuem terras próprias, outras somente os lotes da casa.

O tamanho das propriedades varia entre 22 e 143 hectares, sendo que muitas propriedades têm áreas de morro o que dificulta o acesso e uso da terra. Essas propriedades são 
utilizadas para desenvolvimento da agricultura e da pecuária. Apesar do latifúndio ser um elemento predominante no campo, já se pode notar que esse fato vem contribuindo para a precariedade e para uma determinada dependência dos agricultores camponeses.

Com os trabalhos de campo realizados em Morrinhos, constatamos que se trata de uma comunidade pequena e que vive praticamente da agricultura e da pecuária, contam ainda com o auxílio do governo nos casos de benefícios sociais como o Programa Bolsa Família e a aposentadoria rural.

A produção agrícola é diversificada. Alguns camponeses aplicam os princípios da agroecologia, além da diversificação, preservam a terra e as sementes crioulas da região e não usam insumos químicos nas plantações. Outros já fazem uso de agrotóxicos. Há produção de feijão, milho, abóbora, melancia, mandioca, legumes e hortaliças, também se nota o cultivo de frutas como manga, caju, goiaba e lima e diversas plantas medicinais. Grande parte desses cultivos são feitos nos próprios quintais das casas, quintais agroecológicos com diversas espécies de plantas.

A produção alimentar para o autoconsumo é uma característica das comunidades rurais, tendo em vista que a manutenção da família está diretamente associada à diversidade de atividades na propriedade. A produção para o autoconsumo faz parte deste modo de vida. Plantar, colher e transformar produtos da terra em comida é o processo que assegura a soberania alimentar e a reprodução social das comunidades rurais. (Pereira, 2015).

Apesar das mudanças na comunidade os camponeses preservam características históricas, tais como o modo de organização do trabalho, através das relações de parentesco e mutirões (Figura 1). Essa sociabilidade rural é evidenciada na troca dos produtos como os alimentos da horta, frutas da estação e sementes. Estes momentos de troca de produtos entre as famílias também oportuniza a aproximação e integração entre os vizinhos fortalecendo os laços comunitários. 
Figura 1- Produção em mutirão de Farinha e Goma de Mandioca em Morrinhos.

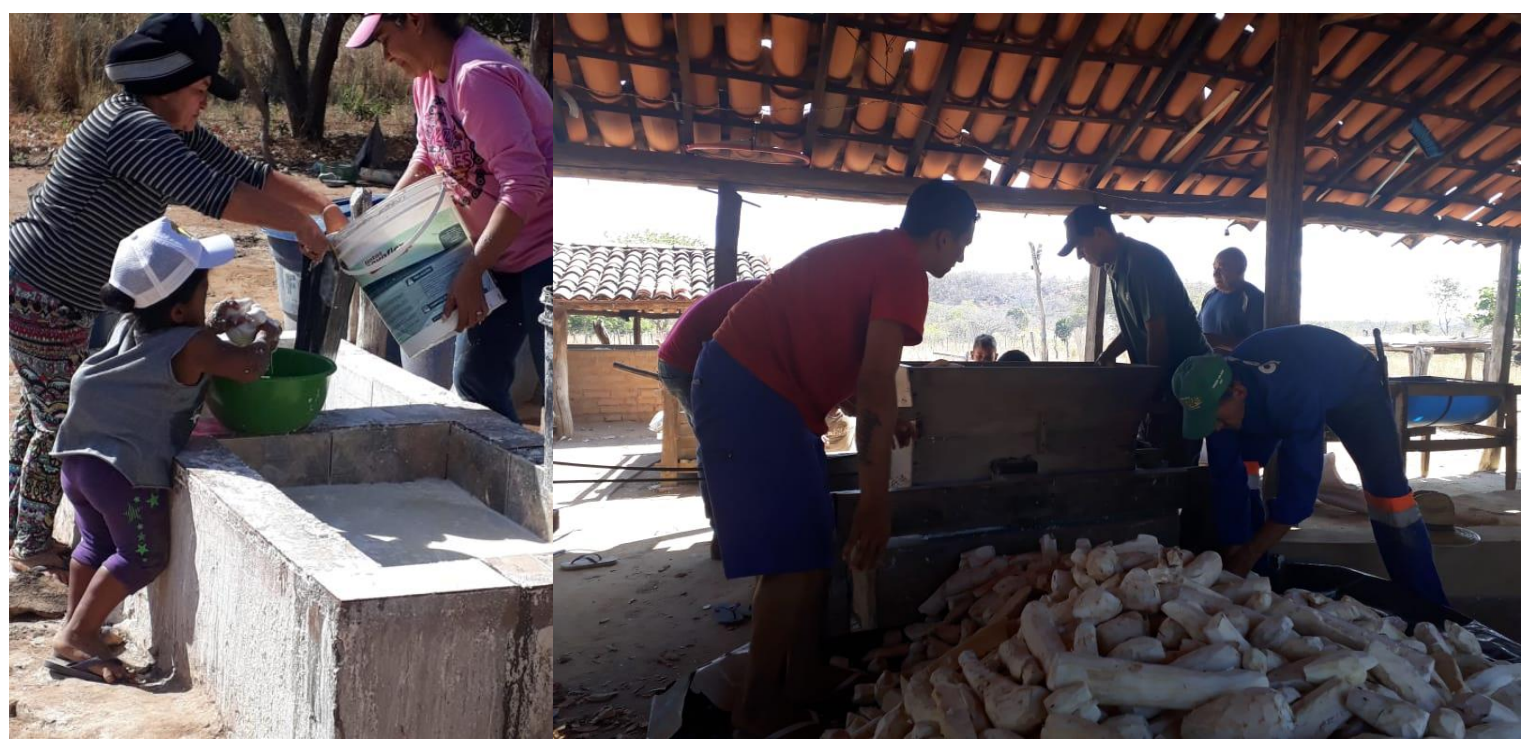

Foto: Adriana Dias de Sousa, 2019.

Dentre as técnicas modernas de produção que já chegaram na comunidade estão os tratores para a arar e gradear a terra, o que ainda não é acessível para todos, pois as máquinas são da Prefeitura de Santa Luz/PI. Como a prefeitura disponibiliza apenas as máquinas e não o combustível muitos não têm condição de fazer o abastecimento no momento que a máquina chega na comunidade.

Assim em Morrinhos ainda é predominante a utilização de recursos manuais, nos quais são exaustivos, mas que garantem a subsistência das famílias. No processo produtivo de preparo da terra, elenca-se que os camponeses ainda utilizam técnicas rudimentares em quase todo o manejo. Apesar da preferência por esses implementos agrícolas, os camponeses afirmaram que está cada dia mais difícil manter a produção com eles, pois devido a idade muitos camponeses não conseguem mais manejá-los, a exemplo do arado puxado a bois.

\section{DA HEGEMONIA DOS IMPÉRIOS ALIMENTARES À HETEROGENEIDADE DO CAMPESINATO: DESAFIOS E CONTRADIÇÕES}

A noção de império trabalhada neste texto é aquela abordada por Ploeg (2008, p. 255). O autor chama atenção para a forma específica em que os processos de globalização estão atualmente se manifestando. De acordo com o autor, "os movimentos globais de pessoas, ideias, 
mercadorias e donativos não são de todo fenômenos novos, mas sua intensidade e velocidade aumentaram dramaticamente". No entanto, essa aceleração em si não explica as mudanças qualitativas que vêm acontecendo em todos os domínios da sociedade. "A essência da atual fase da globalização é que ela introduz, literalmente por toda a parte, conjuntos de normas e parâmetros generalizados que governam todas e quaisquer práticas locais e especificas [grifo nosso]". (Ploeg, 2008, p. 255), a esses conjuntos o autor vai chamar de impérios. Um modo de ordenamento novo e poderoso que reorganiza progressivamente grandes domínios do mundo social e do mundo natural, sujeitando-os a novas formas de controle centralizado e de apropriação massiva.

Ainda para Ploeg (2009, p. 22), os impérios agroalimentares exercem um,

[...] controle 'imperial' direto e crescente sobre a produção e o consumo de alimentos. O capital (ou seja, o valor que é incrementado através da produção da mais-valia) se torna o novo modo de ordenamento dominante para a estruturação da produção agrícola [...].

Contribuindo com essa discussão, Niederle (2008) afirma que no setor agroalimentar, o Império materializa-se em cadeias globais de valor que desconectam quem produz de quem consome, desconectam a atividade agrícola do agroecossistema local, bem como os alimentos produzidos da comida final industrializada.

Desse modo, a relação de confiança antes estabelecida pelo encontro direto entre produtores e consumidores foi substituída. Tem-se em contrapartida os mecanismos de administração de fraudes e riscos alimentares (exemplo do papelão no frango), normas e procedimentos técnicos que homogeneízam e descaracterizam os alimentos.

Ploeg (2008, p. 322) menciona como exemplos, a carne que "já não têm mais relação com a raça, o tipo de alimentação ou ecossistema, pois essas características tornaram-se agora o resultado de processos industriais (injeção de água, proteínas adicionais, amaciadores, sabores artificiais etc.)". E nesse sentido, a agricultura passa a ser simples mercadoria, que não está mais voltada para alimentar a população mundial de forma saudável e sustentável.

Os sistemas agrícolas no mundo atual resultam de três arranjos político-econômicos distintos: a produção capitalista, a agricultura empresarial e a agricultura camponesa. Para o autor a diferença básica entre o modo camponês e o modo empresarial de fazer agricultura reside no grau de autonomia inerente à base de recursos (Ploeg, 2009).

O camponês vive numa complexa relação de autonomia-dependência em relação à terra e em relação a força de trabalho que é basicamente familiar. Assim, no modo de produção camponesa, quanto mais dependente o camponês for em relação à terra mais autônomo será em 
relação ao mercado. Quanto mais membros familiares com força de trabalho disponível mais autônoma e produtiva é a família.

$\mathrm{Na}$ agricultura empresarial a relação ser humano e natureza é distanciada. Embora a natureza continue sendo um ingrediente indispensável, já que é matéria prima, o modo empresarial busca cada vez mais reduzir sua presença priorizando o fator econômico em detrimento do fator ecológico. Segundo Primavesi (1994) o fator econômico não está dissociado do fator ecológico, bem como o ser humano não está dissociado da natureza. E, por isso, o ser humano não pode simplesmente se afastar das leis naturais para dominar, modificar e explorar. Nesse sentido, as regras próprias da natureza, que não funciona de forma mecânica como uma máquina, impedem a padronização do processo de trabalho e torna-se um obstáculo para o aumento em escala e limita (ou atrasa) o aumento da produtividade em função do seu tempo.

Desse modo, a agricultura empresarial busca superar esses limites impostos pela natureza através de um processo universal de artificialização. Exemplos desse processo de artificialização da natureza podem ser encontrados em Altieri (1999) e Gliessman (2002) quando mencionam os pacotes tecnológicos voltados para a modernização da agricultura que vão desde os fertilizantes químicos que substituem a matéria orgânica, os agrotóxicos como herbicidas que controlam o crescimento das plantas espontâneas, as sementes geneticamente modificadas, as tecnologias de inseminação artificial, aos meios de conservação prolongada dos alimentos.

Nesse sentido, observamos que os impérios alimentares não se limitam a área de produção ou consumo, mas abrangem também o complexo de conhecimento científico, no que se refere aos processos produtivos e a integralidade desenvolvida entre instituições e infraestruturas.

Segundo Delgado (2012), muitos analistas que estudam o comportamento internacional das commodities agrícolas, inicialmente na primeira década do século XXI, passaram a visualizar uma verdadeira crise agrária e alimentar. Isto é, muitos países possuem potencial agrícola para garantir sua segurança e soberania alimentar, contudo camponeses e camponesas não têm acesso a terra, nem às condições para desenvolver a agricultura camponesa. Assim, a agricultura empresarial continua com a terra concentrada, produzindo mercadoria e não alimentos.

É nesse sentido que Ploeg (2009) enfatiza que a agricultura camponesa como parte altamente relevante e indispensável da agricultura mundial. $\mathrm{O}$ autor menciona que, 
Em termos quantitativos, os camponeses são a maior parcela, se não a maioria esmagadora da população agrícola do mundo. É enorme e indispensável sua contribuição para a produção de alimentos, a geração de emprego e renda, a sustentabilidade e o desenvolvimento de modo geral. Especialmente sob as condições atuais (crise econômica e financeira global que se combina com crises alimentares periódicas), o modo de produção camponês deve ser valorizado como um dos principais elementos de qualquer que seja o projeto adotado para fazer frente aos dilemas atuais. (Ploeg, 2009, p. 17).

O autor afirma ainda que a terra é central nesse processo porque representa o suporte para atingir um certo nível de independência. Ela é o porto seguro a partir do qual o mundo hostil deve ser encarado e confrontado. Daí vem a centralidade da terra em muitas das lutas camponesas do passado e do presente. Pois, "se de um lado os campesinatos do mundo estão sofrendo com as muitas consequências do ordenamento imperial da produção de alimentos, por outro eles constituem a maior resposta" (Ploeg, 2009, p. 23). Ou seja, as novas e múltiplas formas de resistência que estão surgindo têm menos a ver com as lutas abertas (manifestações, marchas, ocupações, bloqueios) ou com os atos cotidianos da luta velada e camuflada. Há outros campos de ação localizados dentro dos espaços de produção. Nesses campos as estruturas técnico institucionais de trabalho e dos processos produtivos são ativamente alteradas. "Rotinas, ritmos, padrões de cooperação, sequências, mas também máquinas, seus ajustes e misturas de materiais utilizados, são todos alterados visando melhorar o trabalho e os processos produtivos e alinhá-los aos interesses, expectativas e experiências dos trabalhadores envolvidos" (Ploeg, 2009, p. 26).

Diante do exposto, podemos afirmar que existem diversas contradições e conflitos no que se refere aos modos de fazer agricultura. Se de um lado a agricultura empresarial vem se apropriando dos territórios e deixando diversos impactos ambientais e sociais, por outro, a agroecologia tem ressoado por diferentes vias e a agricultura camponesa continua viva e resistente.

\section{SOBERANIA E SEGURANÇA ALIMENTAR E NUTRICIONAL}

Conforme discutido no tópico anterior, a lógica do capital tem buscado convencer os diversos sujeitos do campo a mudarem sua forma de fazer agricultura, no intuito de levar as famílias a dependência de insumos externos como as sementes, fertilizantes, agrotóxicos e outras tecnologias. No entanto, existe um processo vivo de resistência em que esses camponeses vêm desenvolvendo estratégias diversas para se manter no campo, garantir a sua produção e soberania alimentar. 
De acordo com os textos de referência para a II Conferência Nacional de Segurança Alimentar e Nutricional do Conselho Nacional de Segurança Alimentar e Nutricional [Consea] (2004, p. 4), embora o Brasil seja um grande produtor de alimento, parcela significativa da população não tem acesso aos alimentos básicos necessários para a vida cotidiana. Algumas situações de insegurança alimentar e nutricional podem ser observadas a partir de diferentes tipos de problemas, "tais como fome, obesidade, doenças associadas à má alimentação, o consumo de alimentos de qualidade duvidosa ou prejudicial à saúde, estrutura de produção de alimentos predatória em relação ao ambiente natural ou às relações econômicas e sociais; alimentos e bens essenciais com preços abusivos e a imposição de padrões alimentares que não respeitam a diversidade cultural".

Diante desse contexto de insegurança alimentar e das diversas reivindicações da sociedade (organizações instituições civis e governamentais) nasce, durante a II Conferência Nacional de Segurança Alimentar e Nutricional realizada em 2004, na cidade de Olinda, Pernambuco, uma proposta de política pública para tratar dessa problemática. Assim, em 15 de Setembro de 2016, criava-se a LEI N $\mathrm{N}^{\circ}$ 11.346, que estabelece as definiçõos, princípios, diretrizes, objetivos e composição do Sistema Nacional de Segurança Alimentar e Nutricional [SISAN], por meio do qual o poder público, com a participação da sociedade civil organizada, formula e implementa políticas, planos, programas e ações com vistas em assegurar o direito humano à alimentação adequada.

Nesse sentido, o Consea define Segurança Alimentar e Nutricional [SAN] como sendo,

A realização do direito de todos ao acesso regular e permanente a alimentos de qualidade, em quantidade suficiente, sem comprometer o acesso a outras necessidades essenciais, tendo como base práticas alimentares promotoras de saúde, que respeitem a diversidade cultural e que sejam social, econômica e ambientalmente sustentáveis" (Consea, 2004, p. 4).

Associados ao conceito de SAN temos o conceito de Direito Humano à Alimentação e de Soberania Alimentar. O direito à alimentação é parte dos direitos fundamentais da humanidade definidos por um pacto mundial ${ }^{1}$. Esses direitos referem-se a um conjunto de

\footnotetext{
${ }^{1}$ A realização do direito de todos ao acesso regular e permanente a alimentos de qualidade, em quantidade suficiente, sem comprometer o acesso a outras necessidades essenciais, tendo como base práticas alimentares promotoras de saúde, que respeitem a diversidade cultural e que sejam social, econômica e ambientalmente sustentáveis" (Consea, 2004, p. 4). A alimentação foi concebida como um direito fundamental desde a década de 1940, devido ao envolvimento em uma conjuntura que submergiu grandes guerras mundiais e que perpassaram pela insegurança alimentar e nutricional. Desse modo, o Direito à Alimentação foi reconhecido pela Declaração Universal dos Direitos Humanos no ano de 1948, consagrando-se no Pacto Internacional dos Direitos Econômicos, Sociais e Culturais (PIDESC) de 1966 (Paiva et al., 2019).
} 
condições necessárias e essenciais para que todos os seres humanos, de forma igualitária e sem nenhum tipo de discriminação, existam, desenvolvam suas capacidades e participem plenamente e dignamente da vida em sociedade.

A soberania Alimentar diz respeito ao direito que cada país, por sua vez, tem para definir suas próprias políticas e estratégias sustentáveis de produção, distribuição e consumo de alimentos que garantam o direito à alimentação para toda a população, respeitando as múltiplas características culturais dos povos (Consea, 2004).

Dentre outras políticas e programas que foram criados para promover o direito humano a alimentação no Brasil estão: o Programa Nacional de fortalecimento da Agricultura Familiar [PRONAF]; O Programa de Aquisição de Alimento [PAA]; o Programa Nacional de Alimentação Escolar [PNAE] e o Programa Bolsa Família [PBF] (Paixão, 2013).

Apesar de importantes tais políticas ainda são insuficientes para resolver o problema da insegurança alimentar no Brasil, pois se trata de um problema social e político muito complexo. Esses programas mitigam o problema, mas não resolvem. Uma das chaves para resolução que não foi tocada em todo contexto histórico nacional, por exemplo, é uma ampla reforma agrária para possibilitar as famílias os meios de produção (Silva, Calu, \& Silva, 2019).

Vale destacar ainda que, apesar das políticas acima mencionadas beneficiarem em boa medida os camponeses, as políticas voltadas para os impérios alimentares são muito mais amplas e muito mais antigas. De acordo com Conti (2009, p. 28) o governo brasileiro procurou resolver o problema da insegurança alimentar com introdução da Revolução Verde 2 , "uma espécie de campanha de modernização da agricultura mediante o uso intensivo de máquinas, fertilizantes químicos e agrotóxicos para aumentar a produção, e, consequentemente, a humanidade acabaria com a fome". Introduzia-se, assim, o modelo agroexportador centrado nas monoculturas, especialmente da soja, eucalipto, cana-de-açúcar e nos transgênicos, que não favorece a autonomia alimentar, ao contrário, agrava a dependência.

\footnotetext{
${ }^{2}$ A revolução verde foi um processo que se deu a partir da busca por uma produção em larga escala com início na década de 1950, em vários países do mundo, e entre os anos 1960 e 1970 no Brasil. Um ciclo de inovações tecnológicas adquiridas com os avanços do pós-guerra iniciou-se a partir de então, por meio de uma tecnologia de controle da natureza de base cientifico-industrial, sob o pretexto de acabar com a fome no mundo. A Revolução Verde é composta com os pacotes tecnológicos, ou seja, insumos químicos, sementes de laboratório, irrigação, mecanização grandes extensões de terra, conjugado ao difusionismo tecnológico, bem como uma base ideológica de valorização do progresso. (Pereira, 2010 p. 687).
} 
O autor argumenta que a Revolução Verde de fato aumentou a produtividade, mas não cumpriu a promessa de acabar com a fome mundial.

\begin{abstract}
Atualmente mais de setenta países do hemisfério Sul, especialmente na África e na América Latina, são dependentes da importação de produtos agrícolas e não consegue alimentar adequadamente sua população. Em mais de 30 deles ocorreram ou ocorrem conflitos sociais na disputa por alimentos.

Com isso, perderam sua autonomia política e econômica, bem como sua auto suficiência alimentar, ficando vulneráveis às instabilidades da produção e da especulação dos preços internacionais. Para agravar ainda mais a situação, a maioria dos alimentos chegam aos supermercados com resíduos de agrotóxicos e altamente padronizados, pois dessa forma as empresas produtoras ganham em escala e nos lucros. Essa padronização dos alimentos quebra um princípio fundamental de que os alimentos devem ser produzidos de acordo com a natureza e com o modo de vida das pessoas, uma vez que fazem parte da cultura e dos hábitos de cada povo [grifo nosso]. (Conti, 2009, p. 28).
\end{abstract}

Pensando nessa perspectiva da soberania de cada país, percebemos o quão importante é apoiar a agricultura camponesa tradicional de cada lugar. No caso brasileiro, a agricultura camponesa deveria ocupar um lugar muito importante nas estratégias de desenvolvimento que englobe o objetivo da Segurança Alimentar e Nutricional, pois apesar das dificuldades e do apoio insuficiente que recebe do Estado, de um total aproximado de 4,8 milhões de estabelecimentos rurais no Brasil, 4,1 milhões são classificados como unidades familiares. Eles representam cerca de $85 \%$ dos estabelecimentos. Apesar de ocuparem apenas $30 \%$ da área total respondem por $40 \%$ da produção agropecuária nacional. Produção essa voltada basicamente para o consumo interno (Consea, 2004).

Considerando que os alimentos devem ser produzidos de acordo com a natureza e o modo de vida de cada povo. Podemos inferir que a soberania alimentar consiste também no direito de todos os povos participarem das decisões políticas de seu país no que se refere à produção, transformação, distribuição e consumo de alimentos, a fim de que toda a cadeia alimentar esteja em sintonia com os princípios e diretrizes dos direitos humanos de cada povo, num profundo respeito à diversidade cultural e diferentes modos de vida. (Conti, 2009).

Para o autor esse aspecto é importante porque o alimento adquire sua dimensão humana à medida que é transformado em gente saudável e cidadã, gente bem alimentada e nutrida. Assim, o ato de alimentar-se é muito ligado à cultura, à família, aos amigos e aos momentos festivos e celebrativos. "Alimentar-se na companhia de familiares, amigos e parentes, inclusive saboreando pratos típicos e regionais, é também um ato cultural e social que reconstitui continuamente o sentido da existência e a identidade humana”. (Conti, 2009, p. 23). Esse é um ato de cultura que tem se minguado na atualidade, visto que em muitos casos é predominante a 
observância de que as famílias, por uma série de fatores, cada vez menos tem produzido o próprio alimento e dependido cada vez mais dos impérios alimentares.

\section{A RELAÇÃo PRODUÇÃO-CONSUMO NA COMUNIDADE DE MORRINHOS, SANTA LUZ/PI}

Quando analisamos as práticas produtivas da Comunidade Morrinhos fica evidente que os camponeses praticam uma agricultura tradicional e as técnicas usadas são ainda, em sua maioria, manuais e rudimentares. Apesar de estar numa área de fronteira agrícola em que o capital busca modernizar a agricultura, percebe-se que tal modernização não chega para os camponeses quando se trata, principalmente de equipamentos pesados como tratores. Isso acontece porque não existe apoio governamental e crédito para a adesão da comunidade a tais equipamentos.

Da mesma forma nota-se que a assistência técnica não atende a comunidade. O que tem pontos positivos e negativos. Positivos no sentido que é comprovado que a assistência técnica atual é em sua maioria uma assistência que prega a cartilha do capital. Trazendo modelos prontos e não considera a realidade e a lógica camponesa de produção em que nem tudo é mercadoria. Os pontos negativos é que se houvesse uma assistência técnica agroecológica como sugere a Política Nacional de Agroecologia e Produção Orgânica [PNAPO], esses camponeses teriam a oportunidade de inovar e usufruir de tecnologias sociais propostas pela agroecologia.

Os moradores de Morrinhos cultivam no máximo três hectares de terra para produzir o alimento da família e a outra parte, que é morro, usam para o cultivo de pastagem para o gado ou conservam as matas nativas. Praticam uma agricultura em que o trabalho é feito basicamente pelos membros da família e a produção é destinada principalmente para o autoconsumo da família. Quando a safra é considerada boa e há excedente, guarda-se uma parte, para fazer novo plantio no ano seguinte, e a outra é comercializada.

Essa produção para o autoconsumo é naturalmente uma forma de resistência e de enfretamento que os camponeses exercem em relação aos impérios. É quebrar com a lógica de dependência deles e produzir seu próprio alimento. A categoria de camponeses é a única com essa capacidade de enfretamento e, por isso, é marginalizada, invisibilizada e dada como fadada ao desaparecimento por muitos. Daí a importância de entender e refletir sobre o aspecto da segurança e soberania alimentar dos povos do campo. 
Ainda sobre esse aspecto, observa-se uma produção agrícola diversificada. Como a lógica camponesa não considera a produção como uma mercadoria, nota-se que os camponeses nem lembram de todos as variedades da propriedade ou nem contabilizam, mas quando fazemos uma observação nos deparamos com diversas variedades. Dentre os cultivos citados ou observados nas propriedades durante o trabalho de campo estão: feijão, milho, abóbora, melancia, mandioca. Também cultivam frutas como manga, ata, coco, mamão, goiaba, maracujá lima, caju, tomate e hortaliças como coentro, quiabo, cebola, verde, couve, alface, pimentão, e algumas plantas medicinais como hortelã e vik, geralmente nos quintais de casa (Figura 2). O que é comercializado é somente o tomate e as hortaliças que são vendidos na própria comunidade ou na cidade para ajudar na renda da família.

Figura 2- Diversidade produtiva da Comunidade Morrinhos

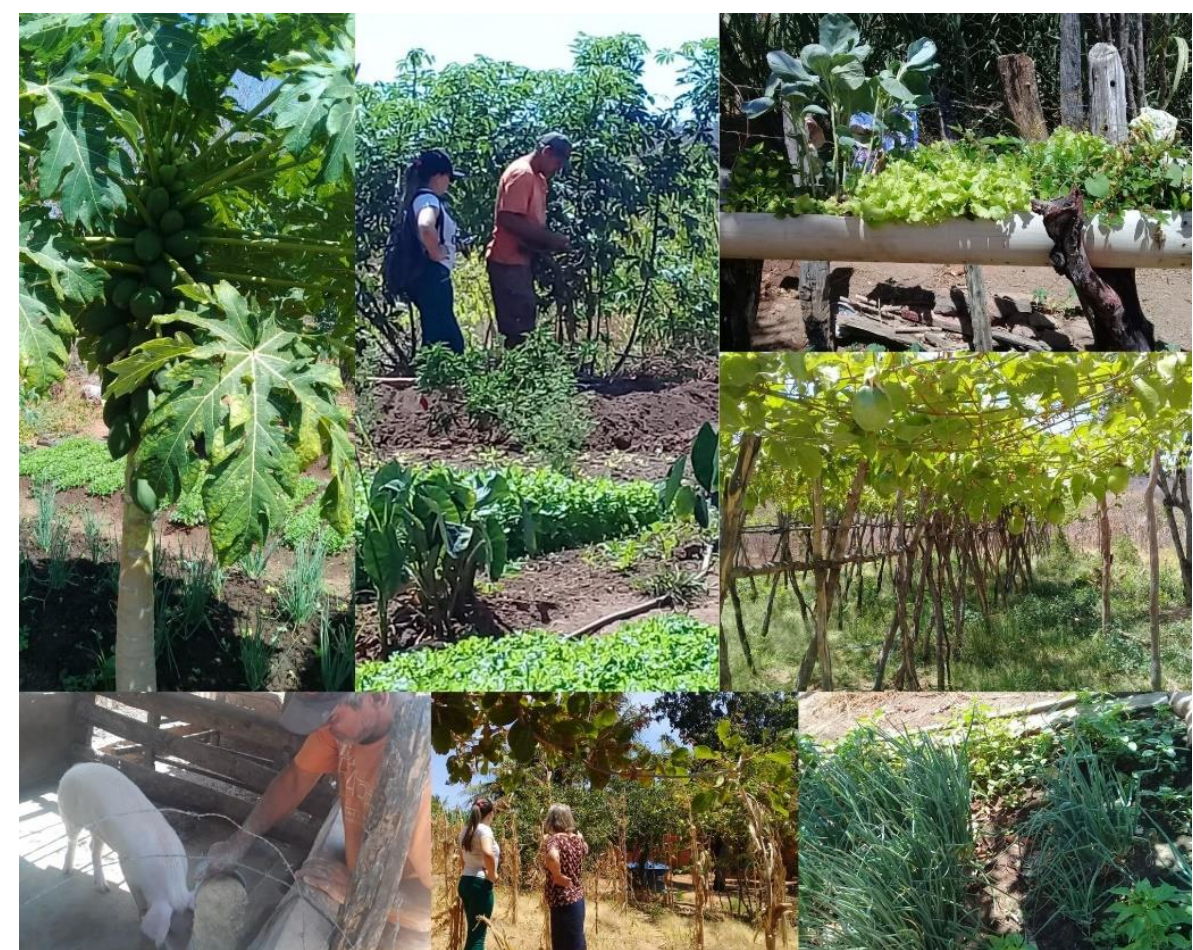

Foto: Adriana Dias de Sousa, 2019.

Assim, como menciona Carvalho (2010) os camponeses devem (e podem), sem a menor dúvida, garantir de maneira continua e crescente as condições efetivas de produção e de organização social para a melhoria da sua qualidade de vida familiar através da produção para o autoconsumo e, ao mesmo tempo, para ampliar a oferta de produtos para os mercados tanto 
para se alcançar à soberania alimentar nacional como para atender às demandas dos produtos da agricultura por outros setores da economia.

Além dos cultivos a comunidade conta com a criação de animais. Os moradores citaram a criação de bovinos, suínos e criação de galinha. Quando analisamos a criação de animais nos chama atenção que diferentemente da produção agrícola, nem sempre os animais são destinados diretamente para a alimentação. Assim eles contribuem indiretamente na segurança alimentar das famílias uma vez que são fonte de renda extra. Os camponeses relatam que consomem os ovos, mas a criação de gado e porco é geralmente destinada para a venda, assim como em algumas situações é a galinha caipira.

Como veremos mais adiante, geralmente os camponeses compram a proteína. E isso nos faz refletir sobre os desafios ainda existente no campo e sobre a entrada de alguns produtos dos impérios alimentares nas comunidades. Um ponto a observar é que para guardar a carne de um porco, por exemplo, o camponês precisaria ter um freezer para armazenamento da carne o que nem sempre é possível dentro da realidade econômica dos camponeses.

Depois, como guardar carne para um mês com uma conta de luz vencendo? Geralmente os animais são uma espécie de poupança para o camponês e ele usa esses recursos de acordo com as necessidades da família. Vende um boi no final do ano quando precisa trocar sua moto (geralmente usada como ferramenta de trabalho e único meio de transporte), ou um porco quando necessita comprar um material escolar para os filhos, ou ainda vende uma galinha caipira para comprar o frango industrializado. Algo que parece completamente contraditório, mas é muitas vezes uma estratégia da família para manter senão a soberania, mas ao menos a segurança alimentar, em termos quantitativos ${ }^{3}$, para a família. Pois com o dinheiro da galinha é possível comprar o frango, mas também outros itens da cesta básica. Essas reflexões têm a ver com as múltiplas dependências, marginalização e privação nas quais o campesinato está inserido.

A partir do exposto acima, percebemos que o modo de produção na comunidade Morrinhos, em sua maioria, segue a lógica camponesa da diversificação e do uso de insumos

\footnotetext{
${ }^{3}$ A compreensão de alimentação adequada, impreterivelmente, remete para a relação entre alimentação e nutrição. Ao se afirmar que uma pessoa se alimenta adequadamente entende-se que ela possui o acesso diário a alimentos em quantidade e qualidade suficiente para atender às necessidades nutricionais básicas de sua vida e saúde. Mas há que se ter cuidado para não reduzir a alimentação a um pacote de nutrientes e calóricos facilmente adquiríveis nos mercados e adotáveis às múltiplas situações para simplesmente matar ou mitigar a fome humana. No mundo crescem as ofertas quase "salvíficas" de "pacotes" sintéticos por parte do mercado de alimentos e medicamentos. (Conti, 2009, p. 23).
} 
locais. Nesse sentido da produção notamos que a comunidade está distanciada dos impérios alimentares. No entanto, vale destacar que alguns camponeses relatam usar algum agrotóxico para o combate de pragas quando essas aparecem. Evidenciando mais uma vez, a relação contraditória entre impérios alimentares e campesinato.

Partindo para a dimensão do consumo de alimentos percebe-se que essas relações de dependência em relação aos impérios alimentares têm aumentado na comunidade nos últimos anos (Figura 3).

Figura 3- Exemplo de produtos adquiridos no mercado pela Comunidade Morrinhos

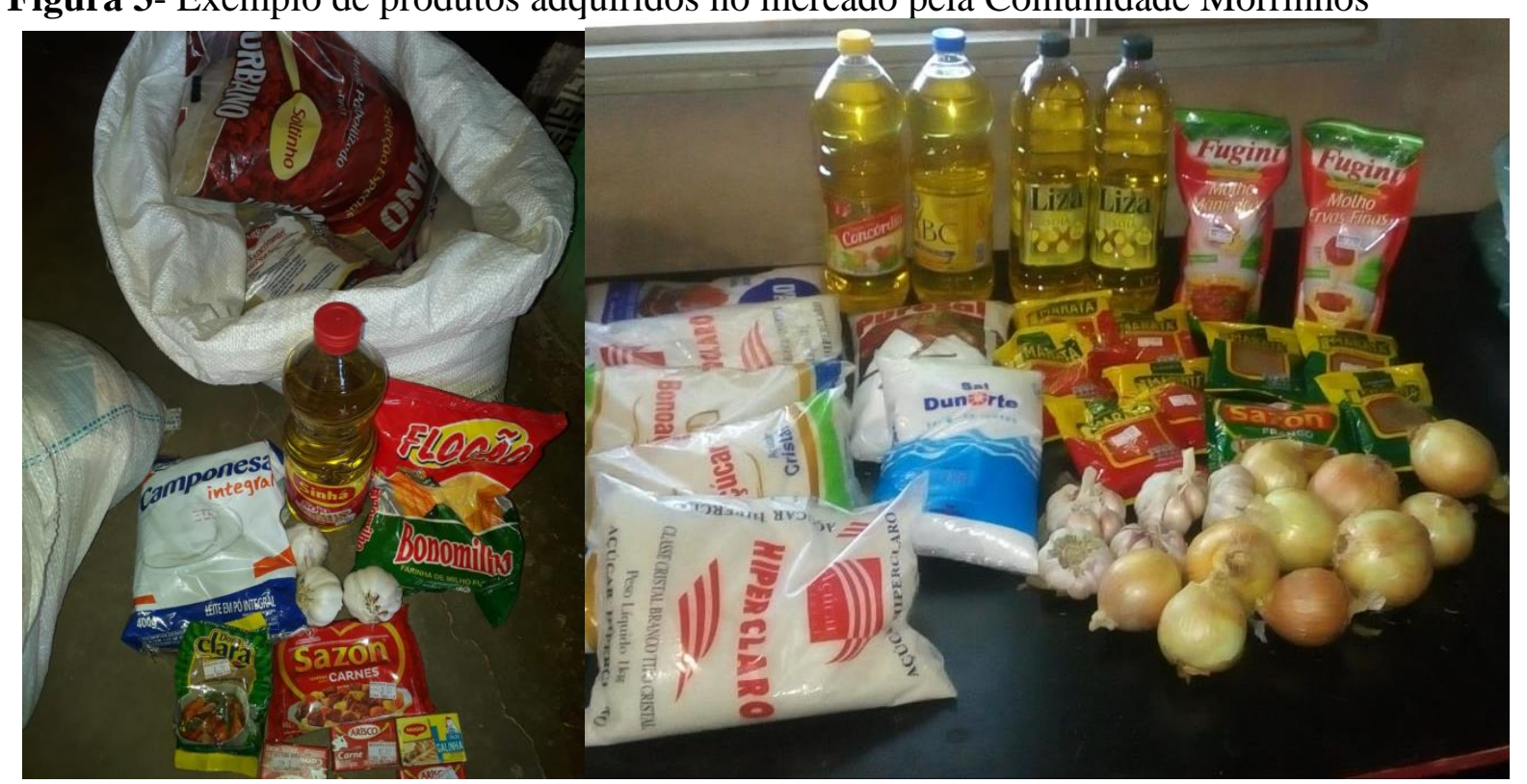

Foto: Adriana Dias de Sousa, 2019.

Dentre os principais produtos estão: leite em pó, açúcar, café, bolachas, bolos, temperos prontos, extratos de tomate, maionese, margarina, óleo de soja, creme de leite, farinha de cuscuz, farinha de trigo, arroz, enlatados como sardinha, processados como linguiça, mortadela e presunto, queijos, frango resfriado, carnes, refrigerantes, macarrão instantâneo, sucos artificiais e leite condensado.

Essas transformações na produção e consumo trazem algumas preocupações, pois como bem menciona Pereira (2015), a cultura alimentar é formada pelas práticas e hábitos alimentares. Ou seja, a cultura alimentar não se refere apenas às raízes históricas, mas, também aos hábitos cotidianos, composto pelo que é tradicional e pelos novos hábitos que vão sendo adquiridos por um grupo social. Assim comer é um ato político, é um ato sagrado que revela 
muito a cultura e a identidade de um povo. Os comportamentos alimentares são adaptados à cultura de cada povo e de cada país, em estruturas fortemente marcadas pelas particularidades locais, com um forte apego à sua própria identidade. Perder a cultura alimentar é perder identidade, mas também perder diversidade biológica.

Quando analisamos a comunidade Morrinhos notamos que alguns hábitos alimentares permanecem, mas outros estão sendo substituídos. Algumas permanências, por exemplo, se referem ao consumo de cuscuz, tapioca e bolo no café da manhã, ou o sagrado feijão com arroz no almoço todos os dias. Alguns já substituem o cuscuz pelo pão ou bolachas de trigo no café. No entanto, além da substituição da forma em que o alimento é preparado existe a preocupação em relação a aquisição dos ingredientes. Nos relatos por exemplo, os camponeses comentam que compram a farinha de cuscuz transgênico ao invés de fazer do milho produzido localmente como em épocas anteriores. Isso acontece pela praticidade, mas também em função do próprio armazenamento. A farinha de cuscuz vem pré-cozida e pode ser armazenada por muito tempo. Além do trabalho exaustivo para preparar a massa de cuscuz de forma artesanal, os camponeses não sabem como armazenar para conservar por vários dias.

Nota-se também que uma estratégia dos comerciantes da cidade é disponibilizar a entrega de mercadoria nas comunidades rurais, o que é considerado como um facilitador no processo de aquisição dos produtos provenientes dos impérios alimentares.

Outro fator relevante para a mudança nos hábitos alimentares é a mídia. Até mesmo os produtos que poderiam ser produzidos na comunidade estão sendo adquiridos no mercado. Um exemplo simples disso é a compra dos extratos de tomate. Muitas camponesas afirmaram comprar o extrato por curiosidade de provar o novo. Desse modo, muitas famílias acabam fazendo substituições como o azeite de babaçu ou banha de porco pela margarina ou óleo de soja; o doce de buriti artesanal pelo doce enlatado de goiaba, dentre outros.

De acordo com Miotto e Oliveira (2006) os meios de comunicação têm grande influência no consumo de alimentos, pois a alimentação engloba tanto a necessidade, quanto o desejo do indivíduo. Hoje, esses meios transmitem aos mais diversos lugares, dados sobre como as pessoas se comportam, se vestem, o que pensam, como aparentam ser, e como se alimentam.

Ainda sobre esse poder da mídia é importante frisar que muitas vezes as famílias não fazem o uso cotidiano de certos alimentos, mas não querem parecer atrasados quando chega uma visita. Então adquire alguns alimentos para ocasiões especiais é o exemplo dos refrigerantes, creme de leite e leite condensado. 
No campo simbólico isso pode resultar de uma das estratégias dos impérios alimentares: a expansão a partir da alteração permanente e múltipla de fronteiras, não apenas as geográficas, mas também as conceituais, por meio da distorção de significados e invenção de comidas e sabores (Ploeg, 2009). Os anúncios de televisão cumprem muito bem esse papel de expansão, pois possuem um forte apelo de marketing visando estabelecer padrão de consumo, atitudes e falsas crenças nutricionais. Uma exposição de 30 segundos a comerciais de TV é suficiente para influenciar a compra de um determinado produto (Santos et al., 2010).

De acordo com os entrevistados está dependência em relação ao mercado também tem a ver com o processo produtivo na comunidade. Os camponeses alegam mudanças na produção, seja em função das mudanças climáticas em que os períodos de chuva estão menos favoráveis ou seja em função do processo delicado de sucessão rural. Pois, muitos jovens da comunidade já não se dispõem em dar continuidade na agricultura e buscam outras atividades ou estudos na cidade. Enquanto isso a população mais idosa não consegue exercer algumas atividades mais exaustivas como o desmanche de mandioca para fazer farinha e o beneficiamento de algumas frutas. O depoimento a seguir evidencia esse fato: "Hoje já existe uma variedade de alimentos que não são produzidos na comunidade. Não produzimos mais o arroz; nem todo mundo produz a farinha de mandioca ou banha de porco que dar lugar ao óleo de soja." (Elizabete, camponesa entrevistada em 27 de setembro de 2019).

É importante ressaltar essa íntima relação entre diversidade cultural e diversidade biológica. Percebe-se que a vulnerabilidade de uma interfere na outra. Quando se reduz a diversidade biológica se reduz a diversidade cultural e vice-versa. Quando os camponeses perdem a cultura de fazer o doce de buriti por exemplo, perde-se também o hábito de consumir esse produto local, consequentemente, abre-se a oportunidade de conseguir os produtos industrializados do mercado como as goiabadas.

Diante de todas as questões colocadas, concorda-se com Ploeg (2008, p. 112) quando afirma que o Império não se sobrepõe apenas no domínio específico da produção e consumo de alimentos. "Através dos impérios alimentares, as práticas de produção, processamento e consumo de alimentos, bem como a organização da circulação de alimentos em todo o globo, estão sendo drasticamente remodeladas”. O Império não se limita apenas em colocar comida na mesa; "ele transforma profundamente os próprios alimentos na forma como foram produzidos e como são consumidos". 
Quando questionados sobre o consumo desses produtos, os entrevistados afirmam que atualmente já não consomem mais alimentos saudáveis, como consumiam antes, havia a inserção, por exemplo, da banha de porco e que agora já cede lugar ao óleo de soja. Eles notam nesse processo de mudança dos hábitos alimentares alguns problemas com a saúde que associam à alimentação, tais como obesidade, diabetes, colesterol alto e hipertensão.

Em poucas palavras, a pesquisa realizada em Morrinhos, constatou a relação contraditória entre os camponeses e os impérios alimentares. Se por um lado mencionamos a produção diversificada desses camponeses garantindo uma relativa autonomia e segurança alimentar e nutricional, por outro percebemos que diversos fatores como as condições climáticas, a sucessão rural e a mídia influenciam na adesão de produtos dos impérios alimentares e com eles muitas vezes a insegurança alimentar e diversos problemas de saúde.

\section{CONSIDERAÇÕES FINAIS}

Conclui-se ao término da pesquisa que existem diversas contradições e conflitos no que se refere aos modos de fazer agricultura. Se de um lado a agricultura empresarial se apropria dos territórios e deixa diversos impactos ambientais e sociais, por outro, a agricultura camponesa continua viva e resistente. Os camponeses apesar das dificuldades praticam uma agricultura em que o trabalho é feito basicamente pelos membros da família e a produção é destinada principalmente para o autoconsumo da família. Essa produção para o autoconsumo se configura como uma forma de resistência e de enfretamento que os camponeses exercem em relação aos impérios ao quebrar a lógica de dependência deles e produzir seu próprio alimento.

Contraditoriamente, a pesquisa enfatiza que diversos fatores como as condições climáticas, a sucessão rural e a mídia influenciam os camponeses na adesão em relação aos produtos dos impérios alimentares e consequentemente esses camponeses sofrem impactos como a própria insegurança alimentar e diversos problemas de saúde.

Nesse sentido, a agroecologia é posta como uma proposta capaz de fortalecer a agricultura camponesa, que é base para a agroecologia numa relação de complementaridade em que ambas atuam com princípios que considera a natureza em sua complexidade, o território e a cultura. Assim, a agricultura camponesa que tem sua base pautada nos princípios da agroecologia desempenha um papel importante para a Segurança Alimentar e Nutricional, para 
a conservação da diversidade biológica e cultural, por isso merece atenção especial por parte das políticas públicas.

\section{REFERÊNCIAS}

Altieri, M. (1999). Agroecología: Bases científicas para una agricultura sustentable. Montevideo: Editorial Nordan-Comunidad,

Carvalho, H. M. (2010, maio). Na sombra da imaginação: reflexão a favor dos camponeses. NERA - Núcleo de Estudos, Pesquisas e Projetos de Reforma Agrária. Recuperado em 21 de setembro de 2019, de http//www.fct.unesp.br/nera.

Conselho Nacional de Segurança Alimentar e Nutricional. (2004). Princípios e diretrizes de uma política de segurança alimentar e nutricional: textos de referência da II Conferência Nacional de Segurança Alimentar e Nutricional. Brasília: Consea.

Conti, I. L. (2009) Segurança alimentar e nutricional: noções básicas. Passo Fundo: IFIBE.

Delgado, N. G. (2012). Commodities agrícolas. In: R. Caldart; I. B. Pereira; P. Alentejano, \& G. Frigotto (Orgs.). Dicionário da educação do campo (pp. 135-143). São Paulo: Expressão Popular.

Falkembach, E. F. (1987, julho/setembro). Diário de campo: um instrumento de reflexão. Contexto e Educação, 2(7), 19-24.

Gliessman, S.R. (2002). Agroecologia: procesos ecológicos en agricultura sostenible.

Turrialba, C.R.: CATIE.

Instituto Brasileiro de Geografia e Estatística. (2017). Cidades. História e Fotos. Disponível em https://cidades.ibge.gov.br/brasil/pi/santa-luz/historico Acesso em: 11 de novembro de 2019.

Instituto Brasileiro de Geografia e Estatística. (2019). Cidades. Panorama. Disponível em https://cidades.ibge.gov.br/brasil/pi/santa-luz/panorama Acesso em: 11 de novembro de 2019.

Marconi, M. A., \& Lakatos, E. M. (2003). Fundamentos de metodologia científica (5a ed.). São Paulo: Atlas.

Martins, A. S. et al. (2002) Piauí: evolução, realidade e desenvolvimento (2a ed.). Teresina: Fundação CEPRO.

Minayo, M. C. S. (Org.). (2001). Pesquisa social: teoria, método e criatividade (18a ed.). Petrópolis: Vozes. 
Miotto, A. N., \& Oliveira, A. N. (2006). A Influência da mídia nos hábitos alimentares de crianças de baixa renda do Projeto Nutrir. Revista Paulista de Pediatria, 24(2), 115-120.

Niederle, P. A. (2008, dezembro). A coreografia do campesinato na sociedade contemporânea. Revista Eletrônica de Ciências Sociais, 2(5).

Paixão, G. R. (2013). Segurança alimentar e nutricional e acesso à água no Norte de Minas Gerais. In: I. L. Conti, \& E. O. Schroeder. Estratégias de convivência com o Semiárido (pp. 175-182). Brasília: IABS.

Pereira, A. B. A. S. (2015). Agricultura familiar camponesa e cultura alimentar: hábitos e práticas alimentares das famílias rurais da linha simonetti - Ivorá/RS. Dissertação de mestrado, Universidade Federal de Santa Maria. Rio Grande do Sul, Brasil.

Ploeg, J. D. (2008). Camponeses e impérios alimentares: lutas por autonomia e sustentabilidade na era da globalização. Porto Alegre: UFRGS.

Ploeg, J. D. (2009). Sete teses sobre agricultura camponesa. In: P. Petersen (Org.). Agricultura familiar camponesa na construção do futuro (pp. 17-31). Rio de Janeiro: AS-PTA.

Primavesi, A. (1994). Manejo ecológico de pragas e doenças: técnicas alternativas para a produção agropecuária e defesa do meio ambiente. São Paulo: Nobel.

Santos, N.S.T.; Nascimento, H.M.A.; Sant'ana; A.M.S.; Lacerda, D.A.L. Influência da mídia nos hábitos alimentares: Trabalhando a educação nutricional no campo da saúde do trabalhador. Anais do V CONNEPI, 2010. Disponível em http://congressos.ifal.edu.br/index.php/connepi/CONNEPI2010/paper/viewFile/1154/660 Acesso em: 12 de setembro de 2019.

Silva, A. R., Calú, A. C. B., \& Silva, V. R. (2019). A reforma agrária como instrumento de poder político: pensando a conjuntura brasileira. In: Anais do Congresso Internacional ALAS Perú 2019: hacia un nuevo horizonte de sentido histórico de uma civilización de vida, Lima, Peru, 32. 